\section{Check for updates}

\section{AUTHORS:}

Eki T. Aisien ${ }^{1}$

Felix A. Aisien²

\section{AFFILIATIONS:}

'Department of Environmental Management and Toxicology, University of Benin, Benin, Nigeria 2Department of Chemical Engineering, University of Benin, Benin, Nigeria

\section{CORRESPONDENCE TO:} Felix Aisien

EMAIL:

aibue.aisien@uniben.edu

DATES:

Received: 24 Mar. 2021 Revised: 30 June 2021 Accepted: 08 July 2021 Published: 29 Nov. 2021

\section{HOW TO CITE:}

Aisien ET, Aisien FA

Photodegradation and kinetics of edible oil refinery wastewater using titanium dioxide. S Afr J Sci. 2021:117(11/12), Art \#10483. https://doi.org/10.17159/ sajs.2021/10483

\section{ARTICLE INCLUDES:}

冈 Peer review

$\square$ Supplementary material

\section{DATA AVAILABILITY:}

$\square$ Open data set

冈 All data included

$\square$ On request from author(s)

$\square$ Not available

$\square$ Not applicable

EDITOR:

Teresa Coutinho iD

\section{KEYWORDS:}

edible oil wastewater, photocatalytic treatment, physicochemical parameters, titanium dioxide, water quality standards

\section{FUNDING:}

None

\title{
Photodegradation and kinetics of edible oil refinery wastewater using titanium dioxide
}

\begin{abstract}
Edible oil refinery wastewater (EORW) is one source of environmental pollution in Nigeria. The treatment of EORW before discharge into the environment remains a significant challenge in the edible oil refinery industries. This research was aimed at photocatalytic treatment of EORW using a batch photocatalytic reactor with titanium dioxide photocatalyst. We investigated the physicochemical parameters: chemical oxygen demand $(\mathrm{COD})$, biological oxygen demand $\left(\mathrm{BOD}_{5}\right)$, oil and grease, phenol, chloride $(\mathrm{Cl})$, total suspended solids, sulfate $\left(\mathrm{SO}_{4}{ }^{2-}\right)$, and phosphate $\left(\mathrm{PO}_{4}{ }^{3-}\right)$ using American Public Health Association methods. The results showed that the reduction efficiency of the treated $\mathrm{EORW}$ with $\mathrm{TiO}_{2}$ catalyst ranged between $65.8 \%\left(\mathrm{PO}_{4}{ }^{3-}\right)$ and $87.0 \%(\mathrm{COD})$, and the improvement in efficiency was $54.1 \%(\mathrm{pH})$ and $60.8 \%$ dissolved oxygen. However, the results showed no significant difference $(p<0.05)$ in the control treatment without catalyst. The biodegradability of EORW increased from 0.196 to 0.32 . It was observed that the optimum values were an initial EORW concentration of $100 \mathrm{~mL} / \mathrm{L}$, irradiation time of $90 \mathrm{~min}$, catalyst dose of $1.25 \mathrm{~g} / \mathrm{L}$, and an agitation speed of $900 \mathrm{rpm}$. The kinetics of the photodegradation process was well described by the pseudo-first-order equation $\left(R^{2}>0.96\right)$ and pseudo-second-order equation $\left(R^{2}>0.98\right)$. The intra-particle diffusion model fairly represented the diffusion mechanism with an $R^{2}$ value of 0.806 . The treated EORW met the most acceptable water quality standards for discharged effluent according to the maximum permissible limits of the Nigerian National Environmental Standards and Regulations Enforcement Agency.

\section{Significance:}

- Photocatalytic treatment of EORW gave negligible results in the absence of a photocatalyst.

- The photocatalytic degradation of EORW improved its biodegradability.

- Photocatalytic treatment of EORW significantly reduced the pollutants in the wastewater.

- The pseudo-first-order equation $\left(R^{2}>0.96\right)$ and pseudo-second-order equation $\left(R^{2}>0.98\right)$ well described the photodegradation process of EORW.
\end{abstract}

\section{Introduction}

There is an enormous consumption of fresh water and energy in the processing of edible oil. Also, unwanted liquid, solid and gaseous wastes are generated together with the desired products (edible oils). ${ }^{1}$ Edible oil refinery wastewater is generated from the degumming, deacidification, and deodorisation and neutralisation processes. $^{2}$ The indiscriminate disposal of this waste and wastewater results in severe environmental pollution and health hazards. Thus, there is an urgent need to manage and treat this waste and wastewater to qualitatively and quantitatively reduce its pollutant loads and reuse the waste and wastewater. The essence of treating large amounts of wastewater generated from edible oil refineries is to remove contaminants before discharge into the environment. ${ }^{3}$ However, edible oil refinery wastewater (EORW) varies in characteristics and quantity from one industry to another. The composition of EORW from the same industry also differs from day to day. ${ }^{4}$

Some researchers have used an activated sludge reactor ${ }^{5}$, electrocoagulation ${ }^{6-9}$, coagulation-flocculation ${ }^{10}$, electrooxidation $^{11}$, and a combination of advanced oxidation processes and biological ${ }^{12}$ methods, for example, in the treatment of EORW, and achieved chemical oxygen demand (COD) removal efficiencies of between $76 \%$ and $99 \%$. Also, Ma et al. ${ }^{13}$ and Kalat and Yüceer ${ }^{14}$ used a biological method to remove $68-99 \%$ oil and grease. Esteves et al. ${ }^{15}$ reported that Fenton's process gave a $96.9 \%$ reduction of phenolic content and biodegradability enhancement. These methods' drawbacks include inadequate removal of dissolved organic matter and nutrients, scarce nitrifying bacteria and low processing load per volume, requirement of expensive equipment, high handling costs, and production of chemical sludge. ${ }^{16,17}$ The EORW contains phenols, heavy metals, catalysts, fats and oils, oxidisable substances, and other complicated dissolved recalcitrant compounds ${ }^{3}$, hence the need to use a physicochemical method such as photocatalysis for its treatment. Liu et al. ${ }^{18}$ and Welz ${ }^{19}$ reported that photocatalytic pretreatment of excess sludge resulted in increased biodegradability of recalcitrant matter, allowing for further treatment of wastewater by continuous biological treatment.

The complexity, characteristic variations, and quantity of EORW have led to the investigation of photocatalytic degradation in this study. Other added advantages of photocatalysis include quick and efficient removal and elimination of organic matter and pathogen $\mathrm{s}^{20}$, mineralisation of a wide range of organic compounds into carbon dioxide, water, and inorganic ions, and intense activity of the process ${ }^{21-23}$. Moreover, its ability to increase the contaminants' biodegradability enable it to integrate with biological methods for process cost-effectiveness. ${ }^{24}$ The biodegradability (biological oxygen demand (BOD)/COD) of organic matter is an important factor for evaluating both the treatability of organic matter in wastewater treatment plants and biogeochemical roles of effluents in the receiving water. ${ }^{25}$ The ratio of $\mathrm{BOD} / \mathrm{COD}$ has been used as a good surrogate for the biodegradability. Biodegradability determines the sustainability and suitability of wastewater for further treatment. ${ }^{26}$ Dhanke and Wagh ${ }^{27}$ reported that 
increasing the biodegradability index is good for biological degradation of wastewater. Nagar and Devra ${ }^{28}$ stated that the use of advanced oxygen processes will increase the biodegradability of textile wastewater by using silver nanoparticles.

The most widely used photocatalyst for the photocatalytic degradation process is titanium dioxide $\left(\mathrm{TiO}_{2}\right)$. It is low cost, non-toxic, chemically stable, environmentally friendly, and has a high oxidative power. ${ }^{29,30}$ However, $\mathrm{TiO}_{2}$ powder is subject to agglomeration that reduces its surface area, hence its catalytic efficiency. Also, there is the difficulty of separation and recovery of the $\mathrm{TiO}_{2}$ catalyst at the end of the photodegradation process. The methods that have been used to address these problems include immobilisation on various supports such as silica, silicon carbide, perlite, fly ash, periwinkle shell ash, zeolites, clay, and activated carbon. ${ }^{31-36}$ The immobilisation of $\mathrm{TiO}_{2}$ on solid supports involves different preparation methods such as hydrothermal, sol-gel, precipitation, metal organic chemical vapour deposition, pyrolysis, impregnation, microwave-assisted synthesis, and sonochemical treatment. ${ }^{37}$ This immobilisation has proven to be very efficient in removing organic contaminants due to the absorptive nature of the $\mathrm{TiO}_{2}$ photocatalyst surface. ${ }^{38}$ The high absorptive efficiency of the $\mathrm{TiO}_{2}$ composite is maintained over a long period. ${ }^{39}$

The problem of contamination of surface and underground water by untreated EORW remains a challenge in Nigeria. Therefore, this study was focused on the efficient removal of pollutants from EORW using the photocatalytic degradation process. We also performed kinetic modelling using pseudo-first-order, pseudo-second-order, and intraparticle diffusion models to determine which of the kinetic model(s) best fit the experimental data. Hence, the research was aimed at investigating the use of photocatalysis for the treatment of EORW and the process kinetics. Our objectives were to evaluate the performance efficiency of $\mathrm{TiO}_{2}$ as a photocatalyst regarding its ability to reduce $\mathrm{BOD}_{5}$ and $\mathrm{COD}$ in EORW and optimise the treatment process through kinetic models.

\section{Materials and methods}

\section{Materials collection}

Three 50-L clean and sterile plastic containers were used to collect raw EORW samples from three discharge points at Egharevbe oil mill in Ebuobanosa-Benin, Nigeria (N6 ${ }^{\circ} 20^{\prime} 1.32^{\prime \prime}{ }^{\circ}{ }^{\circ} 36^{\prime} 0.53^{\prime \prime}$ ). All chemicals/ reagents used, including commercial titanium dioxide $\left(\mathrm{TiO}_{2}\right)[99.5 \%$ anatase], were of analytical grade and purchased from Sigma-Aldrich Co. Ltd (Gillingham, UK), and Qualikems Fine Chemical Ltd (Vadodara, India).

\section{Material preparation}

The EORW samples were preserved at $4{ }^{\circ} \mathrm{C}$ in a refrigerator before treatment. Before commencing treatment, the EORW samples were removed from the refrigerator and held at room temperature $\left(28 \pm 2{ }^{\circ} \mathrm{C}\right)$ for $2 \mathrm{~h}$.

The raw EORW samples were prepared into different initial concentrations by diluting them with deionised water. The initial concentration range was $100 \mathrm{~mL} / \mathrm{L}$ to $250 \mathrm{~mL} / \mathrm{L}$. We prepared the $\mathrm{TiO}_{2}-\mathrm{EORW}$ solution at different concentrations ranging from $0.5 \mathrm{~g} / \mathrm{L}$ to $1.5 \mathrm{~g} / \mathrm{L}$.

\section{Experimental instrumentation}

We used a spectrophotometer 910 model; multi-meter tester 2010 model, HACH colourimeter 402 model, pH meter 3010 model dissolved oxygen meter HI 981193, BOD/COD/total organic carbon meter (Aquadax), and total dissolved solids meter $\mathrm{H} 18734$ to carry out analyses of parameters.

\section{Characterisation of raw edible oil wastewater}

The physicochemical analyses of the raw, control and treated EORW samples were carried out using $\mathrm{AOAC}^{40}$ methods.

\section{Photocatalytic degradation studies}

Photocatalytic studies were performed with a slurry batch reactor. This reactor had a triple jacketed flow through a twin reactors system (Model: MS-H280-Pro). Lelesil Innovative Systems manufactured in India collaborate with the Small Scale Research Group, Faculty of
Engineering, University of Benin, Benin City, Nigeria. The reactor system consists of two 5-L flow-through reactors. These are the primary reactor $A$, inside the photocatalytic reaction chamber, and the secondary reactor B outside. Also present are a peristaltic pump, hot plate with a magnetic stirrer, central jacket for UV lamps, and timer control digital clock. Hence, variables such as flow rate, temperature, agitation speed, UV irradiation, and irradiation time can be measured. ${ }^{31}$

The photocatalytic degradation studies were started by transferring the thoroughly mixed $0.25 \mathrm{~g} / \mathrm{L} \mathrm{TiO}$-EORW solution into reactor $B$ and connecting it to reactor $A$. The flow meter and magnetic stirrer were set at $100 \mathrm{~mL} / \mathrm{min}$ and $900 \mathrm{rpm}$, respectively. We exposed reactor A to a 250W mercury UV lamp, which was the source of UV light, and switched on the reactor system for $30 \mathrm{~min}$. At the end of the reaction time, we collected the treated EORW samples, and centrifuged them at $5000 \mathrm{rpm}$ for solid-liquid separation. A 200-mL supernatant was collected and used to carry out $\mathrm{BOD}_{5}$ and $\mathrm{COD}$ analysis. A similar procedure was used for the control, which was EORW samples without the $\mathrm{TiO}_{2}$ catalyst.

Moreover, we optimised the photocatalytic degradation process of EORW by determining the effects of the initial concentration of EORW, catalyst dose, agitation speed, and irradiation time on the photocatalytic degradation of EORW. The same procedure was followed in each case, varying one of the four variables each time: $100 \mathrm{~mL} / \mathrm{L}$ or $250 \mathrm{~mL} / \mathrm{L}$, $0.25 \mathrm{~g} / \mathrm{L}$ or $1.5 \mathrm{~g} / \mathrm{L}, 300 \mathrm{rpm}$ or $1500 \mathrm{rpm}$, and $20 \mathrm{~min}$ or $90 \mathrm{~min}$, for initial concentration, catalyst dose, agitation speed, and irradiation time, respectively. The $\mathrm{BOD}_{5}$ and $\mathrm{COD}$ for these were subsequently analysed at the end of each experiment.

\section{Analytical methods}

We characterised the raw, control, and treated EORW samples by carrying out analysis of $\mathrm{BOD}_{5}, \mathrm{COD}$, total dissolved solids, dissolved oxygen, phenol, total suspended solids, $\mathrm{Cl}^{-}, \mathrm{SO}_{4}^{2-}$, oil and grease and $\mathrm{PO}_{4}{ }^{3-}$ using standard methods of water analysis. ${ }^{41}$

We calculated the reduction or performance efficiency $(E)$ of pollutant removal from EORW using Equation 1:

$E=\left[1-\frac{c f}{c i}\right] \times 100$

Equation 1

where $C_{\mathrm{f}}$ is final concentration, $C_{\mathrm{i}}$ is initial concentration, and $E$ is reduction efficiency.

\section{Statistical analysis}

Each experiment was done in triplicate and the mean and standard deviation (s.d.) of $n=3$ replicate results were recorded The data were analysed to determine significant differences using the Kruskal-Wallis $\mathrm{H}$-test or one-way analysis of variance by ranks using Statistical Package for Social Sciences (SPSS) version 20 with a significance level of $p=0.05$

\section{Results and discussion}

\section{Characterisation of raw edible oil wastewater}

The characteristics of the raw, control, and treated EORW are summarised in Table 1. The results show that the raw EORW was highly contaminated as expressed by its high $\mathrm{COD}, \mathrm{BOD}_{5}$, oil and grease, total suspended solids, $\mathrm{SO}_{4}^{2-}$, etc. Table 1 shows that the physicochemical parameter values for the raw EORW were above or below the acceptable limits for discharged effluent specified by the Nigerian National Environmental Standard and Regulation Enforcement Agency (NESREA). ${ }^{42}$ This could be because of the presence of chemical compounds such as phenols, heavy metals, catalysts, oxidisable substances, and fats and oils. ${ }^{3,43}$ We observed a significant difference $(p<0.05)$ between the raw or control physicochemical parameters and the treated EORW. However, the results showed no significant difference $(p<0.05)$ in the physicochemical parameters of the raw and control EORW. Moreover, we observed that the photodegradation process reduced $\mathrm{BOD}_{5}, \mathrm{COD}$, total suspended solids, total dissolved solids, oil and grease, phenol, $\mathrm{SO}_{4}{ }^{2-}, \mathrm{PO}_{4}{ }^{3-}$, and $\mathrm{Cl}^{-}$ in the treated EORW by $78.9 \%, 87.6 \%, 76.84 \%, 83.2 \%, 68.6 \%, 83.2 \%$, $65.8 \%$ and $69.3 \%$, respectively. 


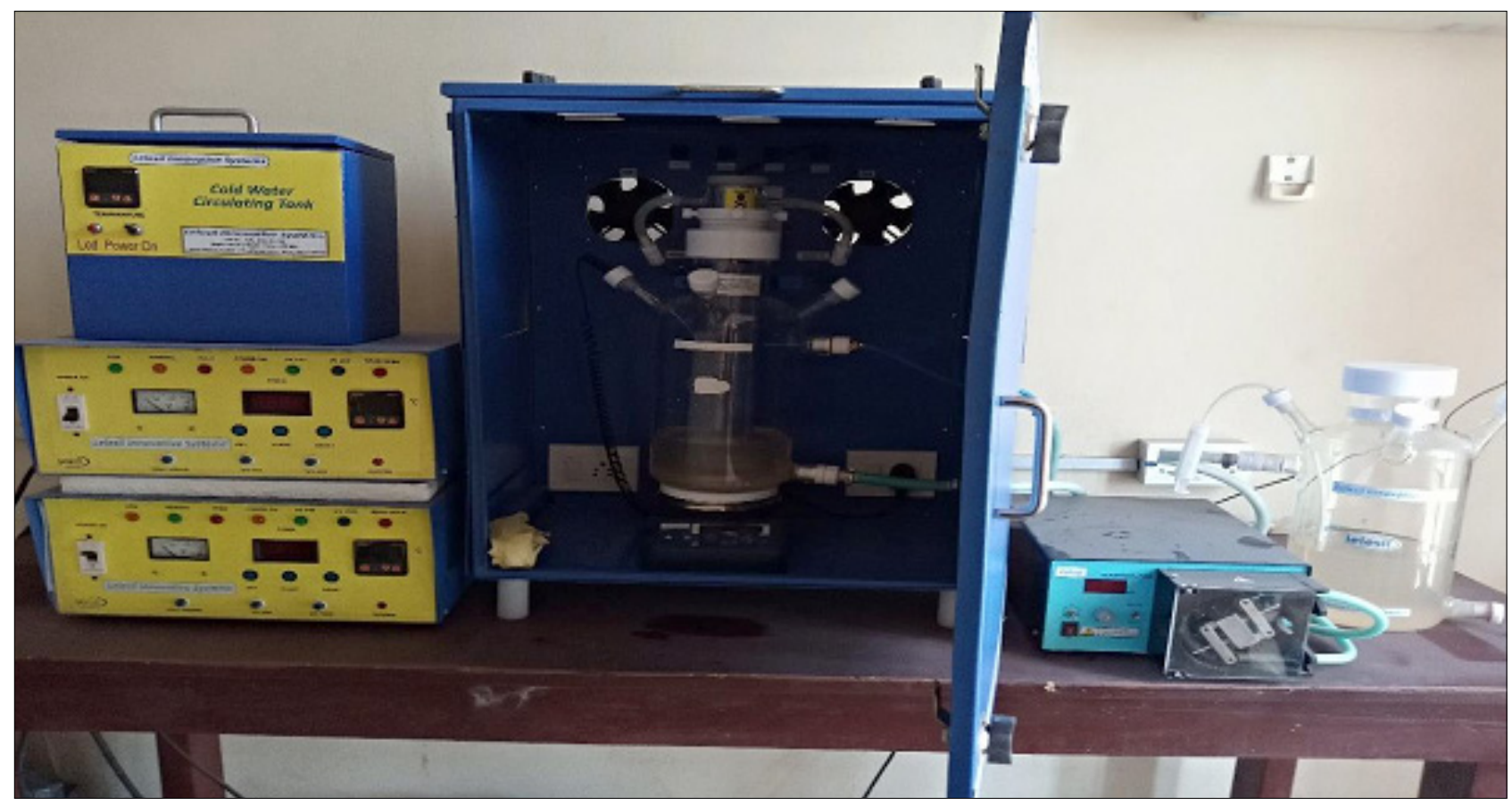

Figure 1: Set-up of the flow-through twin photocatalytic reactors system.

Table 1: Physicochemical characteristics of the raw and treated edible oil refinery wastewater

\begin{tabular}{|c|c|c|c|c|c|}
\hline Parameter & REORW & TEORW1 & TEORW2 & Limit & NESREA \\
\hline $\mathrm{pH}$ & $2.8 \pm 0.05$ & $6.1 \pm 1.3(+54.1)$ & $3.6 \pm 0.42(+22.2)$ & $5.5-12$ & $6-9$ \\
\hline Dissolved oxygen (mg/L) & $1.45 \pm 0.03$ & $3.7 \pm 1.23(+60.8)$ & $1.82 \pm 0.3(+20.3)$ & $>3.0$ & $>5$ \\
\hline Biological oxygen demand $\left(\mathrm{BOD}_{5}\right)(\mathrm{mg} / \mathrm{L})$ & $1620 \pm 52.6$ & $341.8 \pm 18.3(78.9)$ & $1252 \pm 48.1(22.7)$ & 50 & 50 \\
\hline Chemical oxygen demand (COD) (mg/L) & $8265 \pm 74.2$ & $1074.5 \pm 51.7(87.0)$ & $7407.2 \pm 92(10.4)$ & 250 & 90 \\
\hline BOD/COD & 0.20 & 0.32 & 0.17 & & \\
\hline Oil/grease (mg/L) & $670.6 \pm 27.6$ & $218.62 \pm 25.3(67.4)$ & $454.3 \pm 25(32.3)$ & - & - \\
\hline Total dissolved solids (mg/L) & $5920.7 \pm 89.3$ & $994.68 \pm 63.2(83.2)$ & $5364 \pm 76.3(9.4)$ & 400 & 10 \\
\hline Total suspended solids (mg/L) & $1739.2 \pm 71.6$ & $402.8 \pm 58.7(76.84)$ & $1612 \pm 63.5(7.3)$ & 4000 & 500 \\
\hline Phenols (mg/L) & $172.41 \pm 4.8$ & $54.14 \pm 2.4(68.6)$ & $139.7 \pm 13.4(19)$ & 1000 & 30 \\
\hline $\mathrm{PO}_{4}{ }_{4}^{2-}(\mathrm{mg} / \mathrm{L})$ & $96.71 \pm 8.4$ & $33.08 \pm 2.07(65.8)$ & $68.05 \pm 9.7(29.6)$ & 150 & 0.5 \\
\hline $\mathrm{SO}_{4}^{2-}(\mathrm{mg} / \mathrm{L})$ & $2180.3 \pm 75.12$ & $366.24 \pm 1.4(83.2)$ & $1896.7 \pm 76.3(13)$ & 25 & \\
\hline $\mathrm{Cl}(\mathrm{mg} / \mathrm{L})$ & $574.63 \pm 29.5$ & $176.28 \pm 8.4(69.3)$ & $456.5 \pm 36.7(20.6)$ & 1500 & 250 \\
\hline
\end{tabular}

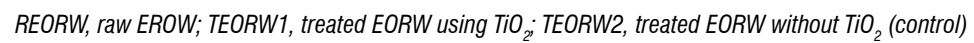

Results in mean \pm s.d., $\mathrm{n}=3$, and percentage reduction or improvement $(+)$ in parentheses.

The $\mathrm{pH}$ and dissolved oxygen increased by $54.1 \%$ and $60.8 \%$, respectively. This suggests that the photodegradation process successfully removed suspended solids, extractable solvents, sulfates, and phosphates. The ratio of BOD/COD for raw and control EORW was 0.196 and 0.17 , respectively. Aslan et al..$^{2}$ reported that vegetable oil wastewater with a low BOD/COD ratio (0.2) contained recalcitrant organic matter. However, Pintor et al. ${ }^{44}$ and Welz et al..$^{45}$ reported a high BOD/COD ratio. They reported that vegetable oil wastewater contains high amounts $(60-83 \%)$ of biodegradable organics; hence it does not require any pretreatment process. The ratio of $\mathrm{BOD} / \mathrm{COD}$ for the treated EORW increased to 0.32 . This shows that the photodegradation process increased its biodegradability; hence further biological treatment methods are highly encouraged. Liu et al. ${ }^{18}$, Esteves et al. ${ }^{15}$, Jamil et al. ${ }^{46}$ and Xing et al. ${ }^{47}$ reported similar results. They stated that photocatalytic pretreatment of excess sludge resulted in increased biodegradability of recalcitrant matter, allowing for further biological treatment of EORW. Also, we found that the physicochemical parameters of the treated EORW were within the acceptable water quality standards permissible for discharged effluent. ${ }^{42}$

\section{Influence of operating parameters on the photodegradation of edible oil wastewater}

\section{Effect of initial concentration}

Figure 2 shows the effect of the initial concentration of EORW on reduction efficiencies of $\mathrm{BOD}_{5}$ and $\mathrm{COD}$. $\mathrm{COD}$ and $\mathrm{BOD}_{5}$ increased from $61.8 \%$ to $76.4 \%$ and $61.8 \%$ to $76.4 \%$, respectively, as the initial 
concentration of EORW reduced from $250 \mathrm{~mL} / \mathrm{L}$ to $100 \mathrm{~mL} / \mathrm{L}$. Therefore, the optimum initial concentration was $100 \mathrm{mg} / \mathrm{L}$. The lower efficiencies witnessed at higher initial concentrations of EORW could be because of the formation of several layers of adsorbed pollutant molecules on the photocatalyst $\left(\mathrm{TiO}_{2}\right)$ surface which inhibits the organic molecules' reaction with the holes or hydroxyl and oxygen free radicals $\left({ }^{\circ} \mathrm{OH}\right.$ and $0^{2-)}$ as the molecules have limited access to these radicals. ${ }^{48}$ Aisien et al. ${ }^{31}$ reported similar results in applying periwinkle shell ash as a photocatalyst for the degradation of naphthalene in an aqueous solution. Therefore, if the initial concentration is increased, the relative ratio of hydroxyl radicals attacking the pollutant decreases, thereby decreasing photocatalytic efficiency. ${ }^{49}$

\section{Effect of irradiation time}

Figure 3 shows the effect of irradiation time on the reduction efficiency of $\mathrm{BOD}_{5}$ and $\mathrm{COD}$ during photodegradation of EORW. We observed a rapid photodegradation of EORW in the first 40 min of the process, as shown by the steep increase in the reduction efficiency of $\mathrm{BOD}_{5}$ and COD. The photodegradation rate continued to increase for another 30 min but less rapidly, and the profile levels off after that, showing that an equilibrium had been reached. At equilibrium, the active sites on the $\mathrm{TiO}_{2}$ particles are occupied by the pollutant molecules, which leads to saturation, hence there is no appreciable increase in photodegradation of EORW. The rapid rate of photodegradation observed in the initial stage of the process may be attributed to the abundant availability of active sites on the surface of the $\mathrm{TiO}_{2}$ photocatalyst. These sites are later occupied by the pollutant molecules as the process progresses, which results in a slowed photodegradation rate in the latter part of the process. Other researchers ${ }^{18,31,48}$ have reported similar results for other wastewater.

\section{Effect of catalyst dose}

The effect of catalyst dose on the reduction efficiency of $\mathrm{BOD}_{5}$ and $\mathrm{COD}$ during photodegradation of EORW in the presence of the $\mathrm{TiO}_{2}$ catalyst is shown in Figure 4. We observed that, using $\mathrm{TiO}_{2}$ as a photocatalyst, the reduction efficiencies of $\mathrm{BOD}_{5}$ and $\mathrm{COD}$ initially increased with an increase in catalyst dose up to maximum values of $70.8 \%$ and $78 \%$ for $\mathrm{BOD}_{5}$ and COD, respectively, at a catalyst dose of $1.25 \mathrm{~g} / \mathrm{L}$. Further increases in catalyst dose resulted in an insignificant increase in reduction efficiencies of $\mathrm{BOD}_{5}$ and $\mathrm{COD}$. This might be attributed to the initial increase in reduction efficiency to lower doses of the catalyst. The catalyst surface and its light absorption are the limiting factors. Hence increasing the catalyst loading enhances the efficiency of the process. This is because of the increase in the number of active sites on the photocatalyst surface, which increases the number of free radicals $\left({ }^{\circ} \mathrm{OH}\right.$ and $\left.\mathrm{O}^{2-}\right)$ produced in EORW..$^{50}$ Aisien et al..$^{31}$ reported similar observations in the photodegradation of aniline using periwinkle shell ash as a photocatalyst. Suri et al. ${ }^{51}$ reported that using a higher dosage of the catalyst might not be advisable.

\section{Effect of agitation speed}

The effect of the agitation speed on the reduction efficiencies of $\mathrm{BOD}_{5}$ and $\mathrm{COD}$ during the photodegradation EORW is shown in Figure 5. We observed that $\mathrm{BOD}_{5}$ and $\mathrm{COD}$ increased from $65 \%$ to $72.2 \%$ and $70 \%$ to $75 \%$, respectively, as the agitation speed increased from $300 \mathrm{rpm}$ to $900 \mathrm{rpm}$. Further increases in agitation speed resulted in decreases in $\mathrm{BOD}_{5}$ and COD. Compared with the effect of irradiation time and catalyst dose, agitation speed had the lowest influence. The optimum agitation speed required for photocatalytic degradation of EORW is $900 \mathrm{rpm}$. This finding is supported by Wu et al..$^{52}$ They stated that the degradation rate increases slightly with agitation speed. The effect of agitation speed can be explained in two ways. Firstly, it is well known that two steps in series govern heterogeneous photocatalysis. Then the overall mass transfer is the summation of the mass-transfer resistance and the chemical reaction resistance. So the increase of the agitation speed leads to a high mass transfer and high degradation rate of pollutants. Secondly, the agitation speed increase can promote oxygen transfer in the liquid phase and thereby increase the degradation kinetics. ${ }^{53}$

\section{Kinetics of photocatalytic degradation of edible oil wastewater}

We studied the photodegradation process kinetics using pseudo-firstorder, pseudo-second-order, and intra-particle diffusion kinetic models.

\section{Pseudo-first-order model}

The pseudo first-order equation is expressed as follows ${ }^{31}$ :

$r=-\frac{\mathrm{d} C}{\mathrm{dt}} \mathrm{kC}$

Equation 2

The pseudo-first-order reaction rate constant, $k$, was obtained from the integrated linear form of Equation 2 as follows:

$k=\frac{\ln \mathrm{C}_{0} / \mathrm{C}_{\mathrm{i}}}{\mathrm{t}}$

Equation 3

where $C_{0}$ is the initial concentration of EORW, and $k\left(\min ^{-1}\right)$ is the pseudo-first-order rate constant.

A plot of In $C_{d} / C_{i}$ versus time $(t)$ resulted in a linear relationship from which $k_{1}$ and $\mathrm{R}^{2}$ were determined from the slope of the graph as shown in Figure 6. The values of the constants are given in Table 2. We observed a linear relationship in Figure 6, which suggests that the pseudo-firstorder equation applies to the photodegradation process. Moreover, we observed that the values of $k$ decreased with an increase in initial EORW concentration. This agrees with the inference made from the results presented in Figure 2 that increasing the initial EORW concentration leads to a reduction in photodegradation reaction rate. According to Daneshvar et al. ${ }^{54}$, a reduction in inactive sites on the catalyst surface may be the reason for the decrease in the rate constant.

\section{Pseudo-second-order model}

The pseudo-second-order kinetic model is expressed in its integrated linear form as follows ${ }^{55}$.

$$
\frac{t}{q_{t}}=\frac{1}{k_{2} q_{e}^{2}}+\frac{1}{q_{e}} t
$$

Equation 4

$h=k_{2} q_{\mathrm{e}}^{2}$

Equation 5

where $k_{2}$ is the rate constant of the pseudo-second-order process (g/mg.min).

The plot of $(t / q t)$ versus $t$ as shown in Figure 7 was used to calculate the values of the model parameters. The kinetic constants calculated are shown in Table 2. High $R^{2}$ values for the pseudo-second-order model can be seen from Figure 7 . The model could describe the photodegradation process kinetics for initial EORW concentration values of $100 \mathrm{mg} / \mathrm{L}$ and $150 \mathrm{mg} / \mathrm{L}$. Beyond these initial concentrations, the model failed to describe the mechanism of the process. However, it is pronounced from Figure 7 that the pseudo-second-order model was the best to represent the kinetics of the photodegradation process, as stated in approximate $1 R^{2}$ values (Table 2 ).

Comparing the pseudo-first-order and the pseudo-second-order kinetic models. We observed that both could successfully describe the kinetic of the photodegradation process of EORW. However, the $R^{2}$ values for the pseudo-second-order are nearer to 1 . It means that the pseudosecond-order model gave the best fit. This suggests that the pseudosecond-order model better represented the photodegradation of EORW than did the pseudo-first-order model.

\section{Intra-particle diffusion model}

The process's diffusion mechanism was modelled using the intraparticle diffusion model as follows ${ }^{56}$ :

$q_{t}=K_{p} t^{1 / 2}+C$

Equation 6

where $K_{\mathrm{p}}$ is the intra-particle diffusion rate constant $\left(\mathrm{mg} / \mathrm{g} \cdot \mathrm{min}^{1 / 2}\right)$ and $C$ is a measure of the boundary layer effect. 


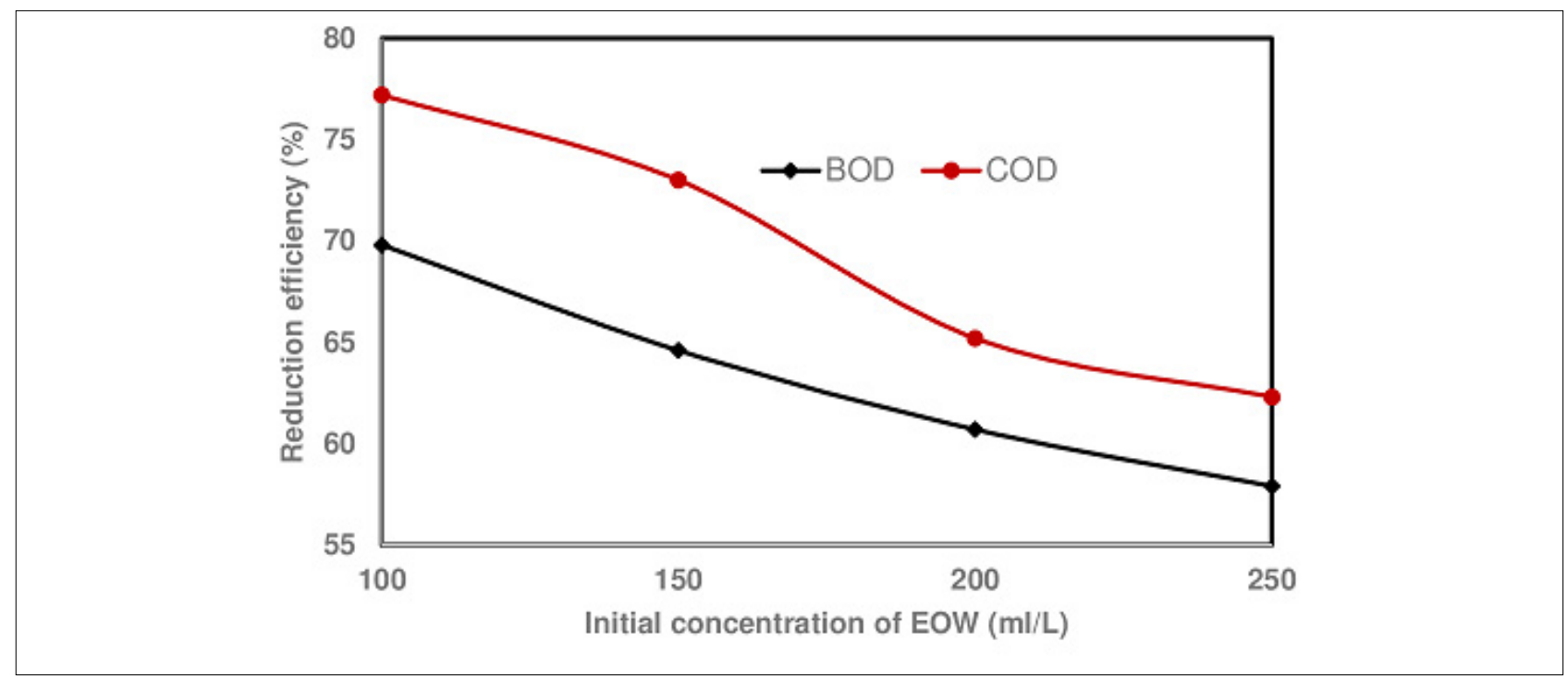

Figure 2: Effect of the initial concentration of the edible oil wastewater (EOW) on the reduction efficiency of biological oxygen demand $\left(\mathrm{BOD}_{5}\right)$ and chemical oxygen demand (COD).

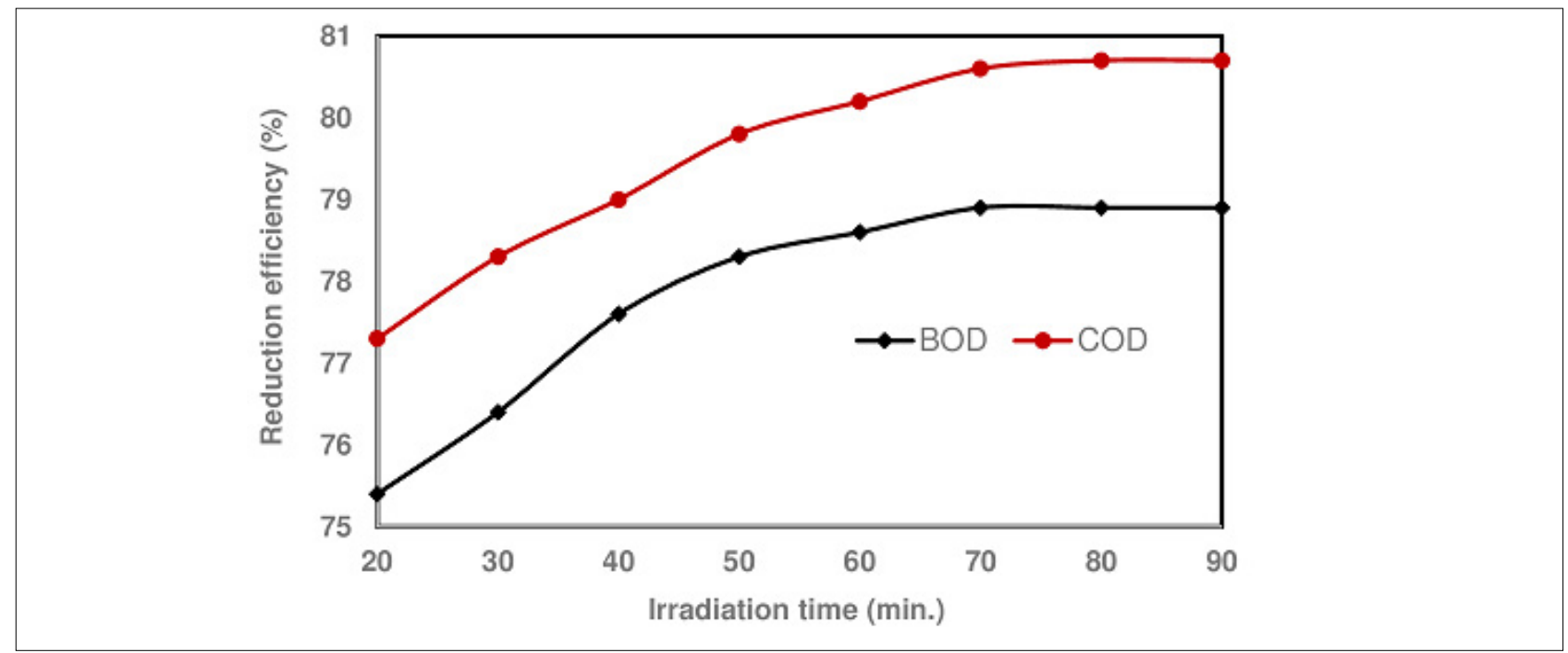

Figure 3: Effect of irradiation time on the reduction efficiency of biological oxygen demand $\left(\mathrm{BOD}_{5}\right)$ and chemical oxygen demand (COD).

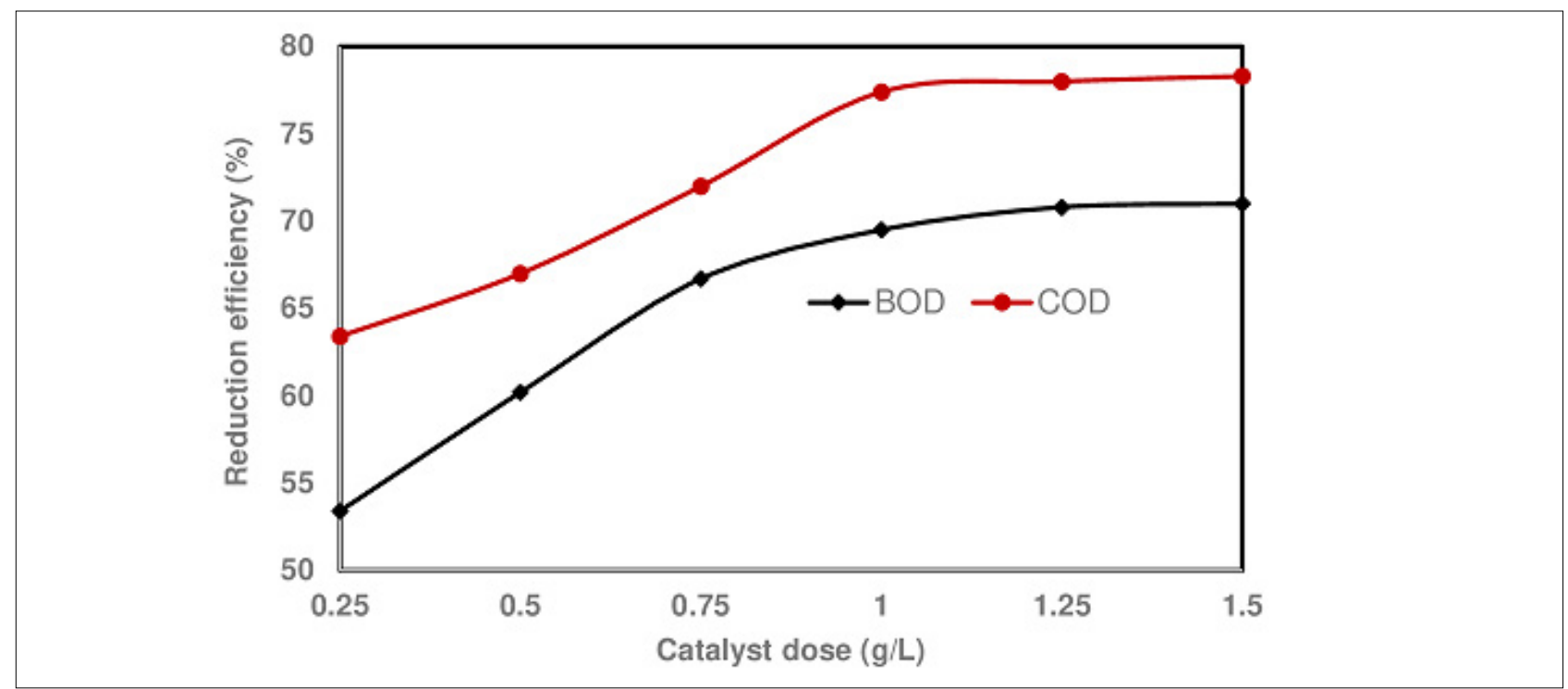

Figure 4: Effect of catalyst dose on the reduction efficiency of biological oxygen demand $\left(\mathrm{BOD}_{5}\right)$ and chemical oxygen demand (COD). 


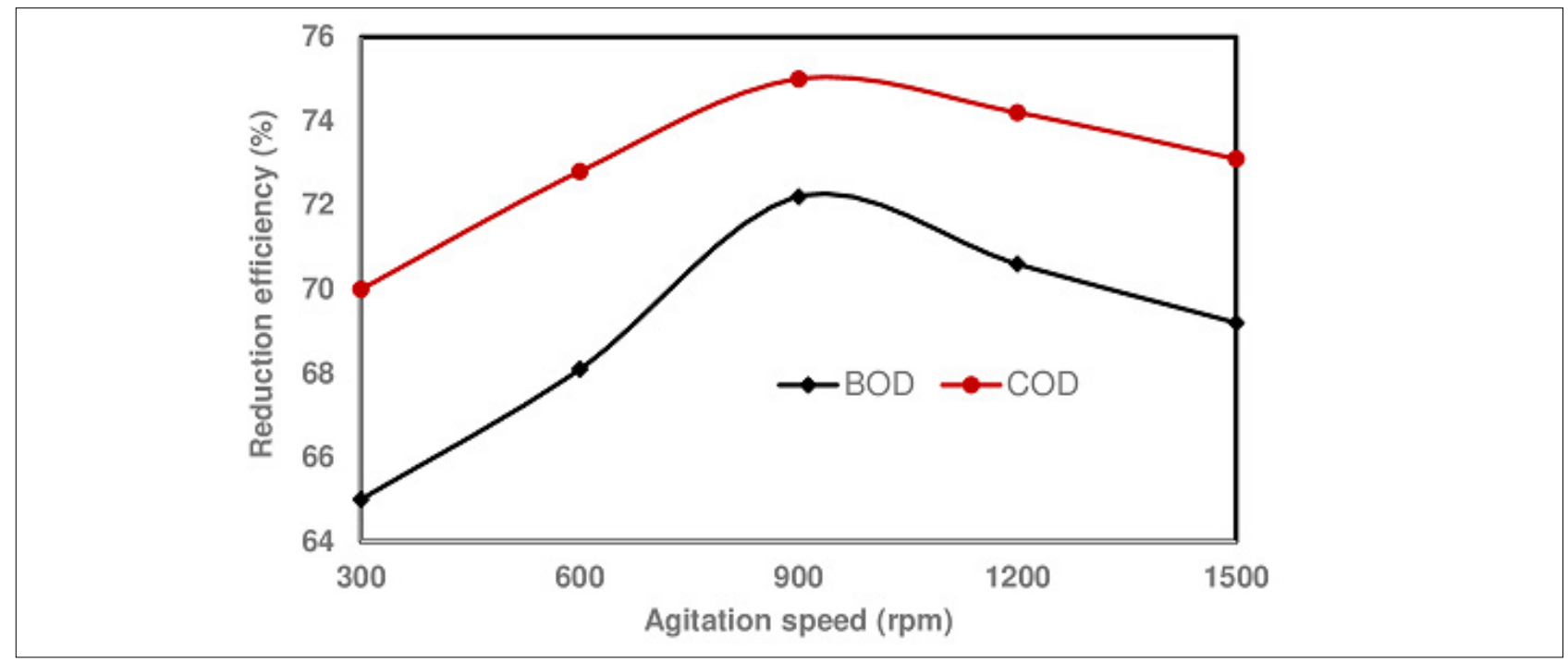

Figure 5: Effect of agitation speed on the reduction efficiency of biological oxygen demand $\left(\mathrm{BOD}_{5}\right)$ and chemical oxygen demand (COD).

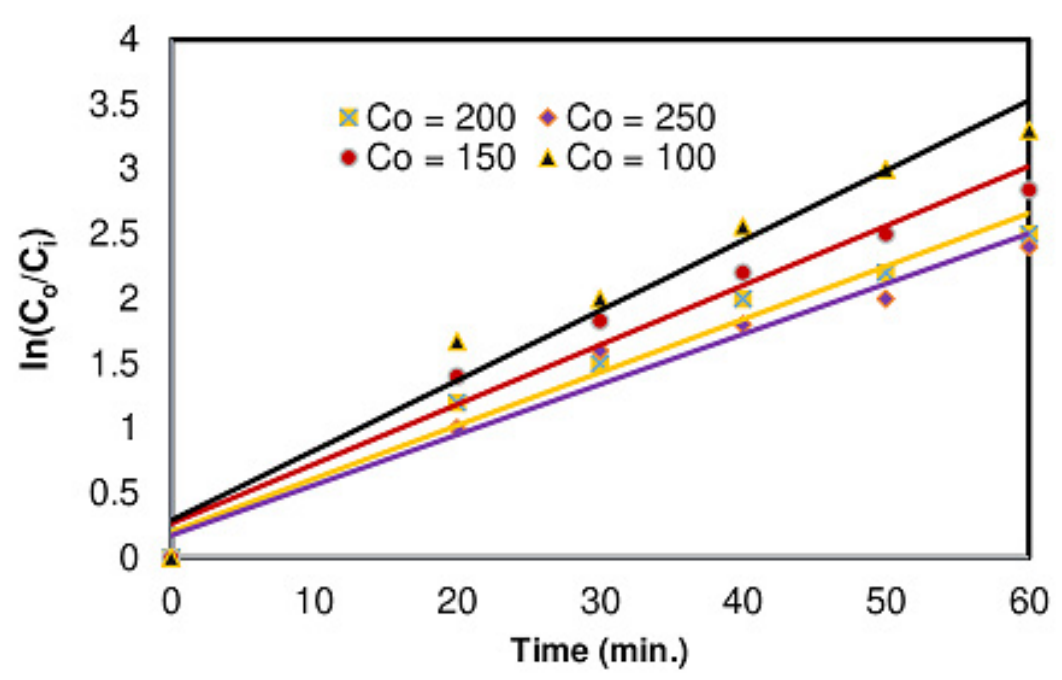

Figure 6: Pseudo-first-order model fitted to batch equilibrium data for edible oil wastewater photodegradation.

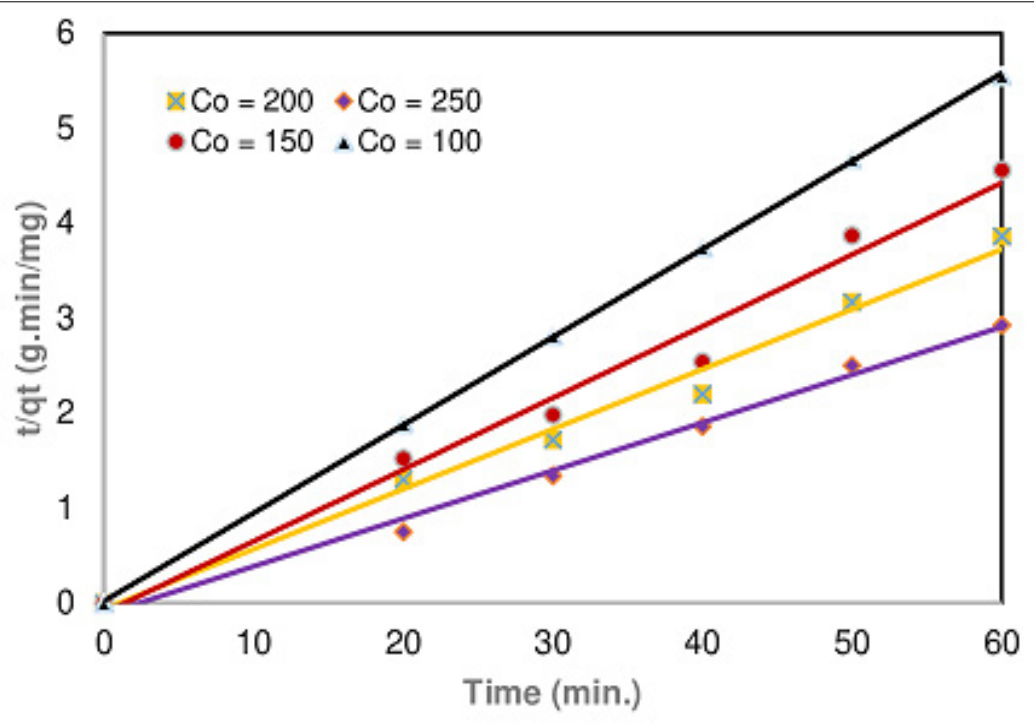

Figure 7: Pseudo-second-order model fitted to batch equilibrium data for edible oil wastewater photodegradation. 
The value of $C$ shows the contribution of the surface sorption to the ratecontrolling step. According to the model, a plot of $q_{\mathrm{t}}$ versus $t^{1 / 2}$ should be a straight line from the origin if the adsorption mechanism follows the intra-particle diffusion only. The values of the intra-particle diffusion model parameters are presented in Table 2. The plot of $q_{\mathrm{t}}$ versus $t^{1 / 2}$ from which we used to calculate the parameters is shown in Figure 8. We observed from Figure 8 that the straight-line plots for the different initial concentrations of EORW investigated did not begin from the origin. In addition, the $R^{2}$ values were lower than shown in Table 2 and Figure 8. The plot shows the existence (although not significant) of some boundary layer effect and further showed that intra-particle diffusion was not the only rate-limiting step. The lower $R^{2}$ values obtained for the kinetic parameters within the concentration range investigated, show that the intra-particle diffusion model was not able to fully describe the diffusion mechanism of the process.

\section{Conclusions}

The following conclusions can be drawn from this study:

1. The characterisation of raw EORW shows it was highly polluted because the physicochemical parameters were outside the acceptable water quality standards for discharged effluent specified by NESREA as maximum permissible limits.

2. The photocatalytic treatment of EORW gave reduction efficiencies ranging between $65.8 \%\left(\mathrm{PO}_{4}{ }^{3-}\right)$ and $87.0 \%$ (COD) and the improvement in efficiency was $54.1 \%(\mathrm{pH})$ and $60.8 \%$ (dissolved oxygen).
3. Photocatalytic treatment of EORW gave a negligible reduction efficiency in the absence of $\mathrm{TiO}_{2}$ as a photocatalyst.

4. The biodegradability of EORW increased from 0.196 to 0.32 after photocatalytic treatment.

5. Optimum values for the process variables were an EORW initial concentration of $100 \mathrm{~mL} / \mathrm{L}$, catalyst dosage of $1.25 \mathrm{~g} / \mathrm{L}$, agitation speed of $900 \mathrm{rpm}$, and irradiation time of $50 \mathrm{~min}$.

6. The catalyst dosage, agitation speed, and irradiation effects on the photocatalytic treatment of EORW were in the order irradiation time $>$ catalyst dosage $>$ agitation speed.

7. The pseudo-first-order and pseudo-second-order kinetic models could describe the kinetics of pollutant removal from EORW using photocatalytic degradation. However, the pseudo-second-order kinetic model gave the best fit, with the highest $R^{2}$ value $\left(\mathrm{R}^{2}>0.98\right)$.

8. The diffusion mechanism is not fully described by the intra-particle diffusion model.

9. The photocatalytic treatment is more effective, cheaper and saves time in comparison to other methods such as chemical and biological methods because of its quick and efficient removal and elimination of organic matter.

\section{Acknowledgements}

We gratefully acknowledge the late Isaac Ayoku Uwagboe for his supervision of the design and fabrication of the photocatalytic reactor system and for his kind provision of the reactor system.

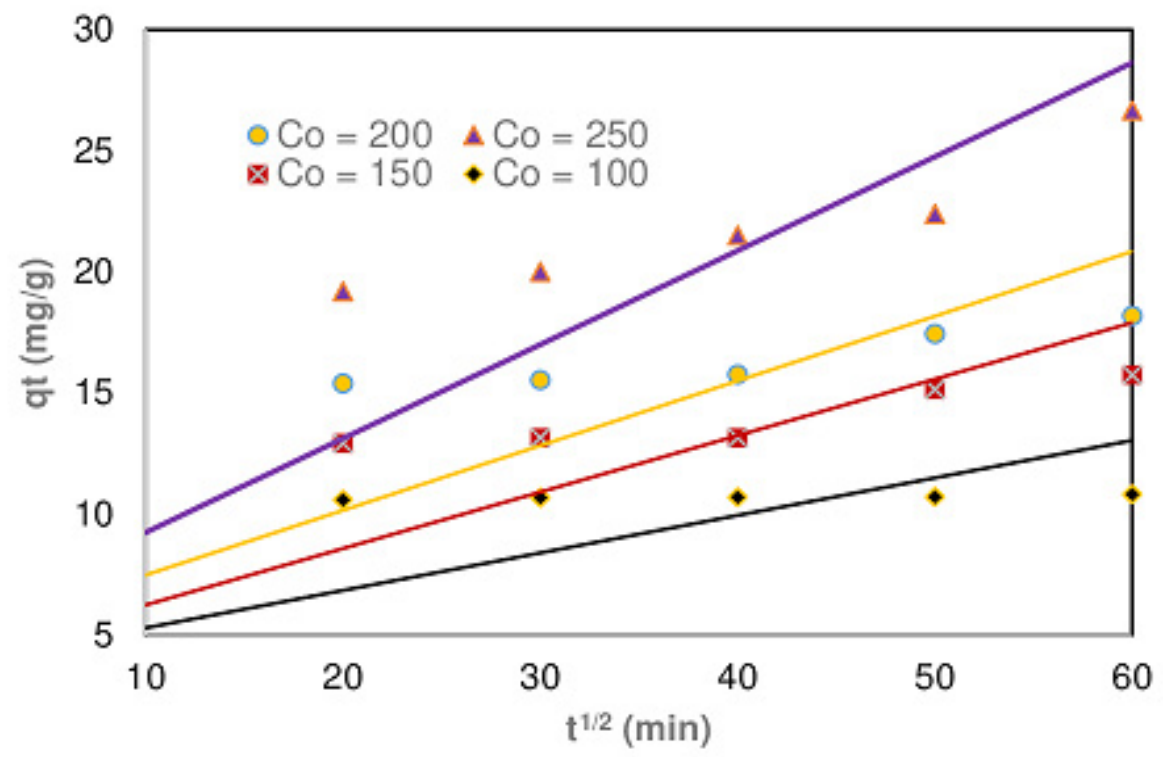

Figure 8: Intra-particle diffusion model fitted to batch equilibrium data for edible oil wastewater photodegradation.

Table 2: Constant parameter values for the photocatalytic degradation kinetics of edible oil refinery wastewater (EORW)

\begin{tabular}{|c|c|c|c|c|c|c|c|c|}
\hline \multirow{2}{*}{ Initial concentration of EORW (mg/L) } & \multicolumn{2}{|c|}{ Pseudo-first-order model } & \multicolumn{3}{|c|}{ Pseudo-second-order model } & \multicolumn{3}{|c|}{ Intra-particle-diffusion model } \\
\hline & $k_{1}$ & $R^{2}$ & $k_{2}$ & $q_{\mathrm{e}}$ & $R^{2}$ & $K_{\mathrm{p}}$ & $c$ & $R^{2}$ \\
\hline 100 & 0.039 & 0.965 & 0.034 & 4.124 & 1.000 & 0.082 & 0.03 & 0.806 \\
\hline 150 & 0.023 & 0.961 & 0.009 & 6.733 & 0.981 & 0.357 & 0.178 & 0.718 \\
\hline 200 & 0.027 & 0.968 & 0.0045 & 9.560 & 0.987 & 0.675 & 0.342 & 0.742 \\
\hline 250 & 0.018 & 0.964 & 0.052 & 16.785 & 0.992 & 0.902 & 0.456 & 0.587 \\
\hline
\end{tabular}




\section{Competing interests}

We have no competing interests to declare.

\section{Authors' contributions}

E.T.A. contributed to the development or design of the methodology and creation of models and conducted the research and investigation process. She was involved in the preparation and creation of the published work, specifically writing, critically reviewing and revising the paper. F.A.A. was responsible for student supervision and oversight of the study. He contributed to the research activity planning and execution, ensured the preparation and creation of the published work, and critically reviewed and revised the paper.

\section{References}

1. Davarnejad R, Sabzehei M, Parvizi F, Heidari S, Rashidi A. Study on soybean oil plant wastewater treatment using the electro-Fenton technique. Chem Eng Technol. 2019;42(12):56-63. https://doi.org/10.1002/ceat.201800765

2. Aslan S, Alyuz B, Bozkurt Z, Bakaoglu M. Characterization and biological treatability of edible oil wastewaters. Pol J Environ Stud. 2009;18:533-538.

3. Velioglu SG, Curi KY, Camililar SR. Activated sludge treatability of olive oilbearing wastewater. Water Res. 1992;25(10):1415-1420. https://doi. org/10.1016/0043-1354(92)90135-q

4. Boyer MJ. Current pollution control practices in the United States. J Am Oil Chem Soc. 1984;61(5):297-309.

5. Tehrani GM, Mahnoudi MM, Borgheipour H, Nezampour A. Evaluation of the efficiency of integrated fixed-film activated sludge reactor for treatment of wastewater from vegetable oil industries. Arch Hyg Sci. 2018;7(3):192-199.

6. Niazmand $\mathrm{R}$, Jahani $\mathrm{M}$, Kalantarian $\mathrm{S}$. Treatment of olive processing wastewater by electrocoagulation: An effectiveness and economic assessment. J Environ Manage. 2019;248, Art. \#109262. https://doi. org/10.1016/j.jenvman.2019.109262

7. Sharma S, Simsek $H$. Treatment of canola-oil refinery effluent using electrochemicalmethods: Acomparison between combined electrocoagulation b electrooxidation and electrochemical peroxidation methods. Chemosphere. 2019;221:630-639.https://doi.org/10.1016/j.chemosphere.2019.01.066

8. Sharma S, Sharma AK, Verma S, Dodiya HS. Treatment of edible oil refinery wastewater by using a chemical and biological process. Int J Eng Sci Res Technol. 2014;3:115-119.

9. Un UT, Koparal AS, Ogutveren UB. Electrocoagulation of vegetable oil refinery wastewater using aluminum electrodes. J Environ Manage. 2009:90:428433. https://doi.org/10.1016/j.jenvman.2007.11.007

10. Dkhissi O, El Hakmaoui A, Souabi S, Chatoui M, Jada A, Akssira M. Treatment of vegetable oil refinery wastewater by coaulation-flocculation using the cactus as a bio-flocculant. Mater Environ Sci. 2018;9:18-25. https://doi. org/10.26872/jmes.2018.9.1.3

11. Šereš Z, Maravič N, Takači A, Nicolič I, Soronja-Simovič D, Jokič A, et al. Treatment of vegetable oil refinery wastewater using alumina ceramic membrane: Optimization using response surface methodology. J Cleaner Prod. 2016;112:3132-3137. https://doi.org/10.1016/j.jclepro.2015.10.070

12. Pazdzior $\mathrm{K}$, Bilinska $\mathrm{L}$, Ledakowicz $\mathrm{S}$. A review of the existing and emerging technologies in the combination of AOPs and biological processes in industrial textile wastewater treatment. Chem Eng J. 2019;376, Art. \#120597. https:// doi.org/10.1016/j.cej.2018.12.057

13. Ma A, Lei T, Ji X, Gao X, Gao C. Submerged membrane bioreactor for vegetable oil wastewater treatment. Chem Eng Technol. 2015;38:101-109. https://doi.org/10.1002/ceat.201400184

14. Kalat DG, Yüceer A. Anaerobic mesophilic and thermophilic treatability of vegetable oil refining wastewater. Process Saf Environ Prot. 2017;109:151157. https://doi.org/10.1016/j.psep.2017.04.001

15. Esteves BM, Rodrigues CSD, Madeira LM. Synthetic olive mill wastewater treatment by Fenton's process in batch and continuous reactors operation. Environ Sci Pollut Res. 2018;25:34826-34838. https://doi.org/10.1007/ s11356-017-0532-y
16. Chen $X$, Mao S. Titanium dioxide nanomaterials: Synthesis, properties, modifications, and applications. Chem Rev. 2007:107:2891-2959. https:// doi.org/10.1021/cr0500535

17. Setvin M, Shi X, Hulva J, Simschitz T, Parkinson GS, Schmid M. Methanol on anatase $\mathrm{TiO}_{2}$ (101) mechanistic insights into photocatalysis. ACS Catal. 2017;7(10):7081-7091. https://doi.org/10.1021/acscatal.7b02003

18. Liu C, Shi W, Kim M, Yang Y, Lei Z, Zhang Z. Photocatalytic pretreatment for the redox conversion of waste activated sludge to enhance biohydrogen production. Int J Hydrogen Energy. 2013;38:7246-7252. https://doi. org/10.1016/j.ijhydene.2013.03.147

19. Welz PJ. Edible seed oil waste: Status quo and future perspectives. Water Sci Technol. 2019;80(11):2107-2116. https://doi.org/10.2166/wst.2020.043

20. Hu X, Hu X, Tang C, Wen S, Wu X, Long J, et al. Mechanisms underlying degradation pathways of microcystin-LR with doped photocatalysis. Chem Eng J. 2017;330:335-371.

21. Poza-Nogueiras V, Rosales E, Pazos M, Sanroma MA. Current advances and trends in electron-Fenton process using heterogeneous catalysts: A review. Chemosphere. 2018;201:399-416. https://doi.org/10.1016/j. chemosphere.2018.03.002

22. Ahmed SN, Haider W. Heterogeneous photocatalysis and its potential applications in water and wastewater treatment: A review. Nanotechnology. 2018;29(34), Art. \#342001. https://doi.org/10.1088/1361-6528/aac6ea

23. Lee SY, Park SJ. TiO ${ }_{2}$ photocatalyst for water treatment applications. J Ind Eng Chem. 2013;19:1761-1769.

24. M'Arimi MM, Mecha CA, Kiprop AK, Ramkat R. Recent trends in applications of advanced oxidation processes (AOPS) in bioenergy production: Review. Renew Sust Energ Rev. 2020; 121, 109669. https://doi.org/10.1016/j. rser.2019.109669

25. Chen B, Nam SN, Westerhoff PK, Krasner SW, Amy G. Fate of effluent organic matter and DBP precursors in an effluent-dominated river: A case study of wastewater impact on downstream water quality. Water Res. 2009;43:17551765. https://doi.org/10.1016/j.watres.2009.01.020

26. Hur J, Lee $\mathrm{TH}$, Lee BM. Estimating the removal efficiency of refractory dissolved organic matter in wastewater treatment plants using a fluorescence technique. Environ Technol. 2011;32:1843-1850. https://doi.org/10.1080/0 9593330.2011 .565078

27. Dhanke P, Wagh S. Treatment of vegetable oil refinery wastewater with biodegradability index improvement Mater Today Proc. 2020;27(1):181-187. https://doi.org/10.1016/j.matpr.2019.10.004

28. Nagar N, Devra V. A kinetic study on the degradation and biodegradability of silver nanoparticles catalyzed methyl orange and textile effluents. Heliyon 2019;5(3), e01356. https://doi.org/10.1016/j.heliyon.2019.e01356

29. Gilja V, Vrban I, Mandic V, Žic M, Murgic ZH. Preparation of a PANI/ZnO composite for efficient photocatalytic degradation of acid blue. Polymer. 2018:10:940-957. https://doi.org/10.3390/polym10090940

30. Zhou Z, Liu X, Sun K, Lin C, Ma J, He M, et al. Persulfate-based advanced oxidation processes (AOPS) for organic-contaminated soil remediation: A review. Chem Eng J. 2019;372:836-851. https://doi.org/10.1016/j. cej.2019.04.213

31. Aisien F, Amenaghawon A, Mededode A. Heterogeneous photocatalytic degradation of naphthalene using periwinkle shell ash: Effect of operating variables, kinetic and isotherm study. S Afr J Chem Eng. 2014;9(1):31-45.

32. Omri A, Benzina M. Almond shell activated carbon: Adsorbent and catalytic support in the phenol degradation. Environ Monit Assess. 2014;186(6):38753890. https://doi.org/10.1007/s10661-014-3664-2

33. Hao D, Yang Z, Jiang C, Zhang J. Photocatalytic activities of $\mathrm{TiO}_{2}$ coated on different semiconductive SiC foam supports. J Mater Sci Technol. 2013;29(11):1074-1078. https://doi.org/10.1016/j.jmst.2013.08.021

34. Kalebaila KK, Fairbridge C. UV photocatalytic degradation of commercia naphthenic acid using $\mathrm{TiO}_{2}$-zeolite composites. J Water Res Prot. 2014;6(12):1198-1206. https://doi.org/10.4236/jwarp.2014.612109

35. Bel Hadjltaief $\mathrm{H}$, Galvez ME, Da Costa P, Ben Zina M. TiO/clay as a heterogeneous catalyst in photocatalytic/photochemical oxidation of anionic reactive blue 19. Arabian J Chem. 2019;12(7):1454-1462. https://doi org/10.1016/j.arabjc.2014.11.006 
36. Ao Y, Xu J, Fu D, Shen X, Yuan C. Low temperature preparation of anatase TiO-coated activated carbon. Colloids Surf A Physicochem Eng Asp. 2008;312(2-3):125-130. https://doi.org/10.1016/j.colsurfa.2007.06.039

37. Omri A, Benzina M, Bennour F. Industrial application of photocatalysts prepared by hydrothermal and sol-gel methods. J Ind Eng Chem. 2015;21:356-362. https://doi.org/10.1016/j.jiec.2014.02.045

38. Takeuchi M, Kimura T, Hidaka M, Rakhmawaty D, Anpo M. Photocatalytic oxidation of acetaldehyde with oxygen on TiO/ZSM-5 photocatalysts: Effect of hydrophobicity of zeolites. J Catal. 2007;246(2):235-240. https://doi. org/10.1016/j.jcat.2006.12.010

39. Takeuchi M, Hidaka M, Anpo M. Efficient removal of toluene and benzene in gas phase by the $\mathrm{TiO}_{2} / \mathrm{Y}$-zeolite hybrid photocatalyst. $\mathrm{J}$ Hazard Mater. 2012;237:133-139. https://doi.org/10.1016/j.jhazmat.2012.08.011

40. AOAC. Official methods of analysis of the association of official analytical chemists. 19th ed. Rockville, MD: AOAC; 2012. p. 234-256.

41. American Public Health Association (APHA). Standard methods for the examination of water and wastewater $\left(22^{\text {nd }}\right)$. Washington DC: APHA; 2012.

42. Nigerian National Environmental Standard and Regulation Enforcement Agency (NESREA). Guidelines and standards for water quality in Nigeria. Abuja: NESREA; 2008.

43. Chipasa KB. Limits of physicochemical treatment of wastewater in the vegetable oil refining industry. Pol J Environ Stud. 2001;10:141-147.

44. Pintor AMA, Vilar VJP, Botleho CMS, Boaventura RAR. Optimization of a primary gravity separation treatment for vegetable oil refinery wastewater. Clean Technol Environ Policy. 2014;16:1725-1734. https://doi.org/10.1007/ s10098-014-0754-3

45. Welz PJ, Le Roes-Hill M, Swartz CD. NATSURV 6: Water and wastewater management in the edible oil industry. 2nd ed. WRC TT 702/16. Pretoria: Water Research Commission; 2017.

46. Jamil TS, Ghaly MY, El-Seesy IE, Souaya ER, Nasr RA. A comparative study among different photochemical oxidation processes to enhance the biodegradability of paper mill wastewater. J Hazard Mater. 2011;185:353358. https://doi.org/10.1016/j.jhazmat.2010.09.041
47. Xing R, Zheng Z, Wen D. Comparison between UV and VUV photolysis for the pre- and post-treatment of coking wastewater. J Environ Sci. 2015;29:45-50. https://doi.org/10.1016/j.jes.2014.10.003

48. Abdollahi Y, Abdullah AH, Zainal Z, Yusof NA. Photodegradation of m-cresol by zinc oxide under visible-light irradiation. Int J Chem. 2011;3(3):31-43. https://doi.org/10.5539/ijc.v3n3p31

49. Kumar DP, Mohamed AR, Bhatia S. Wastewater treatment using photocatalysis: Destruction of methylene blue dye from wastewater streams. J Kejuruteraan. 2002;14:17-30.

50. Konstantinou IK, Albanis $\mathrm{TA}$. $\mathrm{TiO}_{2}$-assisted photocatalytic degradation of azo dyes in aqueous: Kinetic and mechanistic investigation: A review. Appl Catal B Environ. 2004;49:1-14. https://doi.org/10.1016/j.apcatb.2003.11.010

51. Suri R, Liu J, Hand D, Crittenden J, Perram D, Mullims M. Heterogeneous photocatalytic oxidation of hazardous organic contaminants in water. Water Env Res. 1993;65(5):665-673. https://doi.org/10.2175/wer.65.5.9

52. Wu CH, Chang HW, Chem JM. Basic dye decomposition kinetics in a photocatalytic slurry reactor. J Hazard Mater B. 2006;137:336-343. https:// doi.org/10.1016/j.jhazmat.2006.02.002

53. Merabet S, Bouzazab A, Wolbert D. Photocatalytic degradation of indole in a circulating upflow reactor by UV/TiO ${ }_{2}$ process-Influence of some operating parameters. J Hazard Mater. 2009;166:1244-1249. https://doi. org/10.1016/j.jhazmat.2008.12.047

54. Daneshvar N, Aber S, Dorraii MS, Khataee AR, Rasoulifard MH. Preparation and investigation of the photocatalytic properties of ZnO nanocrystals: Effect of operational parameters and kinetic study. Int J Chem Nucl Metall Mater Eng. 2008;1(5):66-71.

55. Ho YS. Review of second-order models for adsorption systems. J Hazard Mater. 2006;B136:681-689. https://doi.org/10.1016/j.jhazmat.2005.12.043

56. Weber WT, Morris JC. Kinetics of adsorption on carbon from solution. J Sanitary Eng. 1963;89(2):31-60. 